\title{
Effects and correlates of continuous training programme on psychosocial status and white blood cell count in men with essential hypertension: A randomized controlled trial
}

\author{
Sikiru Lamina ${ }^{1^{*}}$, Chuba Goddy Okoye $^{2}$, Charles Ikechukwu Ezema ${ }^{2}$, Uche A. Ezugwu ${ }^{3}$, \\ Augustine A. Amaeze ${ }^{3}$, Maduabuchukwu Joseph Nwankwo ${ }^{4}$ \\ ${ }^{1}$ Biomedical Technology Department, School of Health Technology, Federal University of Technology, Owerri, Nigeria; \\ *Corresponding Author: siklam 86@yahoo.co.uk \\ ${ }^{2}$ Department of Medical Rehabilitation, Faculty of Health Sciences and Technology, Enugu Campus, University of Nigeria, Nsukka, \\ Nigeria \\ ${ }^{3}$ Physiotherapy Department, University of Nigeria Teaching Hospital, Ituku Ozalla, Nigeria \\ ${ }^{4}$ Department of Medical Rehabilitation, Faculty of Health Sciences and Technology, Nnamdi Azikiwe University, Awka, Nigeria
}

Received 1 January 2013; revised 1 February 2013; accepted 1 March 2013

Copyright (C) 2013 Sikiru Lamina et al. This is an open access article distributed under the Creative Commons Attribution License, which permits unrestricted use, distribution, and reproduction in any medium, provided the original work is properly cited.

\section{ABSTRACT}

Aim: The aim of this study was to determine the effect and relationship of continuous training programme on WBCc and psychosocial status of black African (Nigerian) subjects with hypertension. Methods: Nigerian subjects with diagnosis of hypertension attending the hypertensive clinic of Murtala Muhammed Specialist Hospital (MMSH), Kano, Nigeria form the population for the study. 217 subjects with mild to moderate (systolic blood pressure [SBP] between 140 - 180 \& diastolic blood pressure [DBP] between 90 - $109 \mathrm{mmHg}$ ) essential hypertension were age matched and randomly grouped into continuous (112) \& control groups (105). The continuous group involved in an 8 weeks continuous training (60\% - 79\% HR max) of between 45 minutes to 60 minutes, 3 times per week, while the controls group remain sedentary. SBP, DBP, WBCc, $\mathrm{VO}_{2} \max$ and psychosocial status were assessed. Student $t$ test and Pearson correlation test were used in data analysis. Results: The study revealed a significant beneficial effect of continuous training programmes on $\mathrm{VO}_{2} \max$, SBP, DBP, WBCc and psychosocial status ( $p<$ $0.05)$. Psychosocial status and WBCc were positively and negatively correlated respectively with $\mathrm{VO}_{2}$ max at $\mathrm{p}<0.01$. Conclusions: This study supports the recommendations of moderate intensity (continuous) training program as an ad- junct multi-therapy in blood pressure, inflammatory and psychosocial stress management in hypertension.

Keywords: Hypertension; Blood Pressure; Psychosocial Stress; Serum Uric Acid; African; Nigerian

\section{INTRODUCTION}

Hypertension is a major global health problem and public-health challenge, demanding a vast proportion of health care resources directly and indirectly because of its high and increasing prevalence and the concomitant risks of cardiovascular and kidney disease, disability-adjusted lifeyears and mortality [1,2]. Various risk factors have been implicated in the development of hypertension, some of which include genetic, environmental, psychosocial, and inflammatory factors $[3,4]$. Links between inflammation and hypertension have been suggested in the past, indeed, various inflammatory markers such as white blood cell (WBC) count have been studied and found to be associated with hypertension and its complications $[5,6]$.

The majority of the biological mechanisms that has been suggested to explain the effect of elevated WBC count on hypertension involve chronic low grade inflammation [7]. Inflammation alters endothelial function, causing inability to produce nitric oxide and prostacycline, which results in the loss of vasodilator, antithrombotic, and antiartherogenic properties of the vascular endothelium $[8$, 9]. Also, stimulated leucocytes have an increased tenden- 
cy to adhere to vascular endothelium, which may cause capillary leucocytosis, and subsequently increase vascular resistance [10]. Elevated WBC count may also be a marker of a state characterized by increased catecholamine levels or sympathetic nervous activities [11]; which can increase blood pressure and may eventually result in sustained hypertension [12].

Studies have found WBC to be inversely related to the physical activity. Physical activity and physical fitness are consistently observed to be associated with reduced chronic inflammation, reflected in lower levels of the inflammatory markers serum C-reactive protein, fibrinogen and white blood cell count, and increased levels of serum albumin (a negative acute phase protein) $[13,14]$. The potential common pathway may be the interleukins (IL) and tumour necrosis factor- (TNF-) which are both released in significant amounts from adipose tissue, particularly visceral adipose tissue. Their release is augmented by increased sympathetic stimulation which is down regulated by regular physical activity; TNF- is a potent stimulator of IL-6 production and IL-6 is a potent stimulator for WBC production [15].

It has also been reported that regular exercise induces anti-inflammatory actions; during exercise, IL-6 (interleukin-6) is produced by muscle fibres. 20 - 23 IL-6 stimulates the appearance in the circulation of other antiinflammatory cytokines such as IL-1 ra (interleukin-1 receptor antagonist) and IL-10 (interleukin-10) and inhibits the production of the proinflammatory cytokine, TNFalpha. The suppression of inflammatory reaction by exercise may further result in biochemical, neural, and hormonal changes in the blood vessel walls that induce blood vessel relaxation. The blood vessels relax after each exercise session because of body warming effects, the local production of certain chemicals, such as lactic acid and nitric oxide, decreases in nerve activity and changes in certain hormones and their receptors [16]. Over time, as the exercise is repeated, there is growing evidence of a long-lasting effect

Numerous studies report the beneficial effects of habitual physical activity (PA) on more traditional disease risk factors such as hypertension [17] but less is known about its effect on inflammation; since a single bout of exercise induces an inflammatory response that is similar to that induced by infection or trauma [18]. It is questionable whether long-term PA may be effective for reducing chronic inflammation, especially in hypertension. Also, data from numerous smaller studies suggest that regular PA has the potential to reduce circulating levels of several inflammatory biomarkers [19]; yet to date, there are very limited data from randomized controlled trials to definitively conclude that long-term regular exercise training reduces chronic inflammation and on the relationship of WBC, psychosocial status and hypertension. More so, studies have implicated genetics, race and ethnicity in the aetiology and biomarkers of inflammation in hypertension [20-23]. These interpersonal and interracial differences clearly indicate the needs for study on pure older black African population. For the purpose of this stu$\mathrm{dy}$, three hypotheses were formulated and tested:

1) There would be significant correlations between baselines (pretest) WBCc and other variables such as BP, $\mathrm{VO}_{2} \mathrm{max}$ and psychosocial status.

2) There would be significant differences between experimental and control groups in blood pressure (BP), psychosocial status and WBC.

3) Changes in $\mathrm{VO}_{2} \max$ would significantly correlate with changes in BP, psychosocial status and WBC.

\section{METHODOLOGY}

\subsection{Research Design}

The study design was age matched randomized independent-control group (pretest-posttest) design. The study duration was eight weeks.

\subsection{Population and Subjects}

Population for the study was male essential hypertensive subjects attending the hypertensive clinic of Murtala Muhammed Specialist Hospital, Kano, Nigeria. Subject were fully informed about the experimental procedures, risk and protocol, after which they gave their informed consent in accordance with the American College of Sports Medicine (ACSM) [24], guidelines, regarding the use of human subjects as recommended by the human subject protocol. Ethical approval was granted by the Ethical Committee of Kano State Hospitals Management Board. Sample size was determined using the sample size calculator by Creative Research System Survey Software (CRSSS) (Petaluma, CA, USA).

\subsection{Inclusion Criteria}

Only those who volunteered to participate in the study were recruited. Subjects between the age range of 50 and 70 years with chronic mild to moderate and stable $(>1$ year duration) hypertension (SBP between $140-180 \&$ DBP between $90-109 \mathrm{mmHg}$ ) were selected. Only those who had stopped taking antihypertensive drugs or on a single antihypertensive medication were recruited [24]. They were sedentary and have no history of psychiatry or psychological disorders or abnormalities.

\subsection{Exclusion Criteria}

Obese or underweight (BMI between $20 \& 30 \mathrm{~kg} / \mathrm{m}^{2}$ ), smokers, alcoholic, diabetic, other cardiac, renal, respiratory disease patients were excluded. Those involved in vigorous physical activities and above averagely physically fit $\left(\mathrm{VO}_{2} \max >27 \&>33 \mathrm{ml} / \mathrm{kg} \cdot \mathrm{min}\right.$ for over $60 \&$ 
50 years old respectively) were also excluded.

A total of 323 chronic and stable, essential mild to moderate male hypertensive patients satisfied the necessary study criteria. Subjects were aged matched and randomly grouped into experimental (162) and control (161) groups.

\section{PROCEDURE}

Research design: In the present study, age matched randomized double blind independent groups design was used to determine the influence of the continuous training program on cardiovascular parameters.

\section{PRETEST PROCEDURE}

Wash out Period: All subjects on antihypertensive drugs were asked to stop all forms of medication and in replaced, were given placebo tablets (consisted of mainly lactose and inert substance) in a double blind method [24, 25]. Also subjects including those not on any antihypertensive medications were placed on placebo tablets for one week (7 days); this is known as "wash out period". The purpose of the wash out period was to get rid of the effects of previously taken antihypertensive drugs/medications. During the wash out period all subjects were instructed to report to the hypertensive clinic for daily blood pressure monitoring and general observation. The Pretest and posttest procedures were conducted at the last day of the wash out period.

\subsection{Physiological Measurement}

Subjects resting heart rate (HR), SBP, and DBP were monitored from the right arm as described by Musa et al. [26] using an automated digital electronic BP monitor (Omron digital BP monitor, Medel 11 EM 403c; Tokyo Japan).

\subsection{Anthropometric Measurement}

Subjects' physical characteristics (weight $[\mathrm{kg}]$ \& height $[\mathrm{m}]$ ) and body composition (body mass index [BMI] $\left.\left(\mathrm{kg} / \mathrm{m}^{2}\right)\right)$ assessment was done in accordance with standardized anthropometric protocol (International Society for the Advancement of Kinanthropometry [ISAK] [27].

\subsection{Blood Sample Collection (Venipuncture Method)}

Both pre and post treatment venous blood samples were obtained after about 12 hour overnight fast (fasting blood sample). Five $\mathrm{ml}$ syringe was used for blood sample collection, using the procedure described by Bachorik [28]. About $5 \mathrm{ml}$ of blood was drawn from the antecubital vein of each subject under strict antiseptic condition. One milliliter of blood sample was immediately transferred into a special container containing anticoagulant (heparin, 75
$\mathrm{U} / \mathrm{ml}$ ) for WBC count. All samples were stored in a refrigerator at $-80^{\circ} \mathrm{C}$ until analysis [29].

\subsection{White Blood Cell Count}

The WBC count was done using Turks method as described by Dacie and Lewis [30].

\subsection{Psychosocial Assessment}

Subjects were in a comfortable sitting position and were presented with a questionnaire tagged the General Well Being Schedule (GWBS). Subjects were instructed to respond to the subscales of the 18 items questions. Subjects were timed for a maximum of 20 minutes and the questionnaire collected immediately. High values indicate high psychosocial wellbeing or decrease psychosocial stress. The questionnaire was developed and validated by the National Centre for Health Statistics [31].

\subsection{Stress Test}

The Young Men Christian Association (YMCA) submaximal cycle ergometry test protocol was used to assess subject's aerobic power $\left(\mathrm{VO}_{2} \max \right)$ as described by ACSM [32]. The stress test (pre \& post training) was conducted under the supervision of experts in basic life support care and the emergency unit of the hospital was made ready to accommodate any incident that might occur during the stress test.

The YMCA protocol uses two to four 3-minutes stages of continuous exercise, two HR-power output data points will be needed (steady state HR) of between 110 and 150 beat $/ \mathrm{min}$. The two steady state HR were plotted against the respective workload on the YMCA graph sheet. A straight line was draw through the two points and extended to the subjects predicted maximum HR (220-Age). The point at which the diagonal line intersects the horizontal predicted HR max line represents the maximal working capacity for the subject. A perpendicular line was dropped from this point to the baseline where the maximal physical workload capacity was read in $\mathrm{kg} \cdot \mathrm{m} \cdot \mathrm{min}^{-1}$, which was used to predict the subjects $\mathrm{VO}_{2}$ max. This procedure was done for both pre and posttest stress test.

\section{TEST PROCEDURE}

\subsection{Training Programme}

Following stress test and prior to the exercise training, all subjects in both control and continuous groups were re-assessed by the physician and were prescribed with antihypertensive drug; methyldopa (aldomet) as necessary. Aldomet was preferred because it does not alter normal haemodynamic responses to exercise [33] and it is a well-tolerated antihypertensive drug in the Africa [34] and mostly prescribed in the northern part (Kano) of the 
country where the study was conducted and useful in the treatment of mild to moderately severe hypertension [35]. Subjects maintain these prescriptions with regular medical consultation and observation through-out the period of exercise training.

\subsection{The Continuous Group (Group 1)}

Subjects in the continuous group exercised on a bicycle ergometer at a low intensity of between $35 \%-59 \%$ of their HR max as recommended by ACSM [36]. The starting workload was $100 \mathrm{kgm}$ (17 watts) which was increased at a pedal speed of $50 \mathrm{rpm}$ to obtain a HR max reserve $35 \%$ was increased in the first two weeks to and level up at 59\% HR max reserve throughout the remaining part of the training period. The initial of exercise session was increased from 45 minutes in the first two weeks of training to and leveled up at 60 minutes throughout the remaining part of the training. Exercise session of three times per week was maintained throughout the 8 weeks training period for continuous group.

\subsection{The Control Group (Group 2)}

Subjects in the control group were instructed not to undertake any vigorous physical activity during the 8 weeks period of study.

\section{POSTTEST PROCEDURE}

Wash out Period: At the end of the 8 weeks training period, all subjects were asked to stop methyldopa (aldomet) and subjects were prescribed with placebo tablets for one week as in pretest procedure. Post training SBP, DBP, CRP, WBC count, assessment feeding and stress test were conducted as earlier described in the pretest procedures using standardized protocols, techniques and methods.

All pre and post test measurements were recorded on a data sheet. Two hundred and seventeen subjects (112 from continuous, and 105 from control group) completed the eight weeks training program. One hundred and six subjects (50 from continuous, and 56 from control group) had dropped out because of non-compliance, unfavorable responses to methyldopa and exercise training or had incomplete data; therefore, the data of 217 subjects were used in the statistical analysis (Figure 1).

\section{Statistical Analysis}

Following data collection, the measured and derived variables were statistically analyzed. The descriptive statistics (Mean, standard deviations and \% change) of the subjects physical characteristics, estimated $\mathrm{VO}_{2} \max , \mathrm{WBC}$ count, cardiovascular parameters were determined. Students' t test and Pearson product moment correlation test were computed for the variables of interest. All statistical analysis was performed on a Toshiba compatible microcomputer using the statistical package for the social science (SPSS), (Version 16.0 Chicago IL, USA). The probability level for all the above tests was set at 0.05 to indicate significance.

\section{RESULTS}

The subject's age ranged between 50 and 70years. Mean age, height, weight and BMI: of subjects in continuous exercise group were $(58.63 \pm 7.22$ years, $1.73 \pm$ $6.97 \mathrm{~m}, 67.49 \pm 10.16 \mathrm{~kg}, 22.48 \pm 2.89 \mathrm{~kg} \cdot \mathrm{m}^{-2}$ ) respectively while for the Control group Mean age, height, weight and BMI were $(58.27 \pm 6.24$ years, $1.68 \pm 5.31 \mathrm{~m}$, $68.47 \pm 17.07 \mathrm{~kg}, 23.37 \pm 5.31 \mathrm{~kg} \cdot \mathrm{m}^{-2}$ respectively). There was no significant difference in age $(\mathrm{t}=0.390, \mathrm{p}=$ 0.697), baseline SBP $(\mathrm{t}=0.540, \mathrm{p}=0.597)$, baseline DBP $(\mathrm{t}=0.530, \mathrm{p}=0.597)$, and baseline $\mathrm{VO}_{2} \max (\mathrm{t}=$ $-0.406, p=0.685)$ between groups. The physical characteristics of the subjects are comparable (Table 1).

Groups pre and post treatment mean $\mathrm{BP} \pm \mathrm{SD} \mathrm{mmHg}$; psychosocial status, WBCcSUA (x 10/mm) and $\mathrm{VO}_{2}$ max $\mathrm{ml} \cdot \mathrm{kg}^{-1} \cdot \mathrm{min}^{-1}$ are depicted in Table 2. Changed score values and Students' $t$ test results (Table 3 ) indicated a significant effect in the exercise groups over control in $\operatorname{SBP}(\mathrm{p}=0.000), \operatorname{DBP}(\mathrm{p}=0.040)$, psychosocial status $(\mathrm{p}$ $=0.000)$, WBCc $(\mathrm{p}=0.000)$ and $\mathrm{VO}_{2} \max (\mathrm{p}=0.000)$ at $\mathrm{p}<0.05$.

There was significant correlation between $\mathrm{WBCc}$ and other variables: SBP $(\mathrm{r}=0.344)$; $\mathrm{DBP}(\mathrm{r}=384)$; $\mathrm{VO}_{2} \mathrm{max}$ $(\mathrm{r}=-0.247)$; Psychosocial status $(\mathrm{r}=-0.202)$ Figure 2 . There was a significant positive and negative correlation between changes between changes in $\mathrm{VO}_{2}$ max and changes in psychosocial status $(\mathrm{r}=0.729)$ and changes in WBCc $(\mathrm{r}=-0.418)$ respectively at $\mathrm{p}<0.01$ (Figure 3 ). There was also significant negative correlation between changes in psychosocial status and changes in $\mathrm{WBCc}(\mathrm{r}=-0.202)$ at $\mathrm{p}<0.05$ (Figure 4).

\section{DISCUSSION}

The purpose of this study was to test the hypotheses that: there would be significant correlation between baselines (pretest) WBCc and other baseline (pretest) variables such as $\mathrm{BP}, \mathrm{VO}_{2} \max$ and psychosocial status. Secondly, there would be significant difference between experimental and control groups in blood pressure (BP), psychosocial status and WBC. Finally, changes in $\mathrm{VO}_{2}$ max would significantly correlate with changes in BP, psychosocial status and WBC. All the hypotheses were supported by the results of the present study.

Findings from the present study revealed a significant decrease in SBP, DBP, WBC and increase in $\mathrm{VO}_{2}$ max in the continuous group over control group. The favorable 


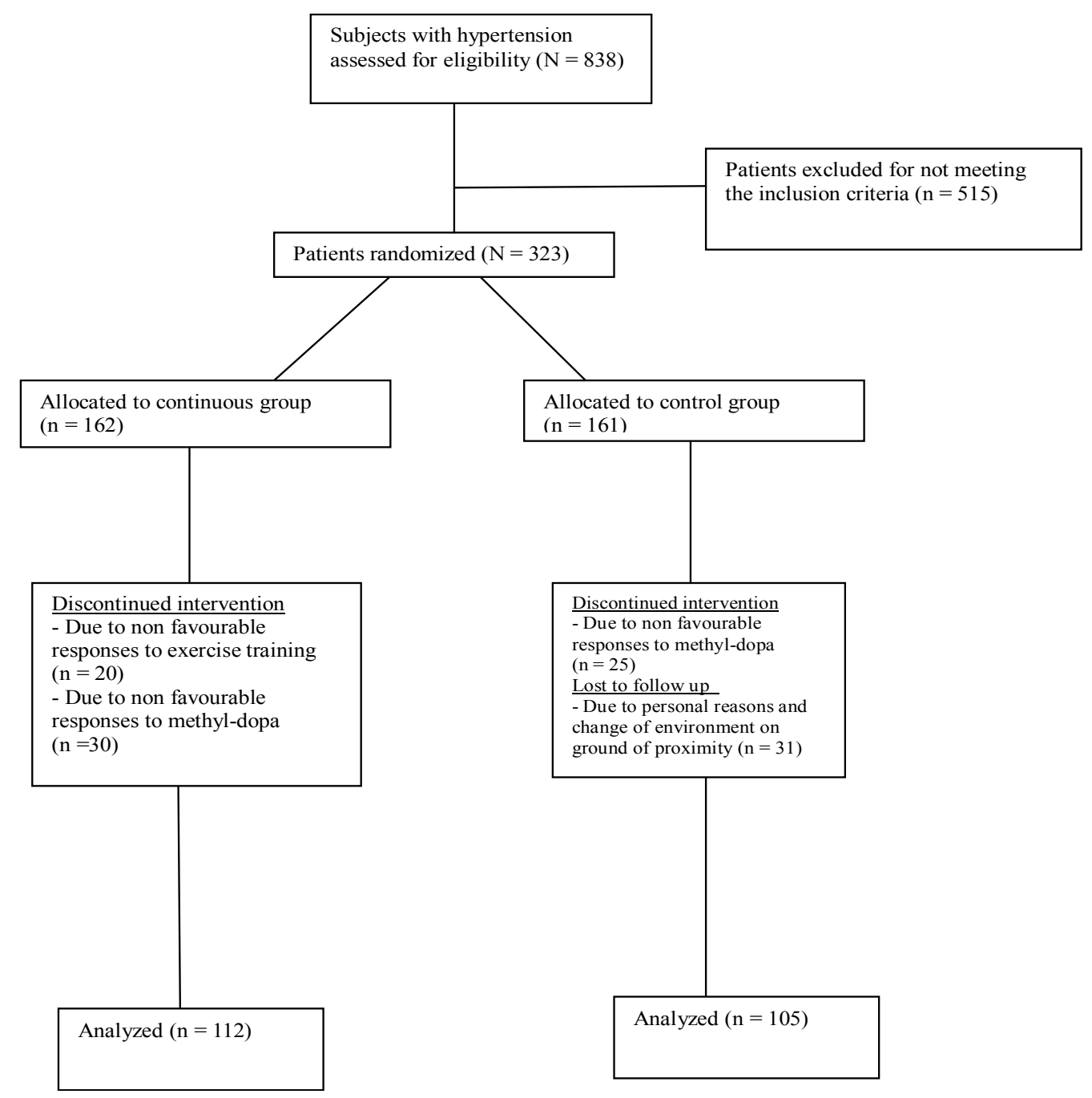

Figure 1. Study design flow chat.

Table 1. Groups mean \pm SD base line characteristics and Independent t-test $(\mathrm{N}=217)$.

\begin{tabular}{|c|c|c|c|c|}
\hline Variables & $\begin{array}{l}\text { Continuous group } \\
(n=112) X \pm S D\end{array}$ & $\begin{array}{l}\text { Control group } \\
(n=105) X \pm S D\end{array}$ & t-values & p-values \\
\hline Age (years) & $58.63 \pm 7.22$ & $58.27 \pm 6.24$ & 0.390 & 0.697 \\
\hline $\mathrm{SBP}(\mathrm{mmHg})$ & $170.45 \pm 15.57$ & $160.87 \pm 13.23$ & 0.540 & 0.597 \\
\hline $\mathrm{DBP}(\mathrm{mmHg})$ & $97.56 \pm 7.53$ & $97.17 \pm 1.43$ & 0.530 & 0.597 \\
\hline $\mathrm{VO}_{2} \max (\mathrm{ml} / \mathrm{kg} / \mathrm{min})$ & $20.69 \pm 12.49$ & $21.23 \pm 5.76$ & 0.406 & 0.685 \\
\hline Weight (kg) & $67.48 \pm 10.16$ & $68.47 \pm 17.07$ & -0.514 & 0.608 \\
\hline $\operatorname{BMI}\left(\mathrm{kg} / \mathrm{m}^{2}\right)$ & $22.92 \pm 2.20$ & $23.37 \pm 3.87$ & -1.060 & 0.290 \\
\hline
\end{tabular}

*Significant, $\mathrm{p}<0.05$.

changes resulting from aerobic training in both SBP and DBP demonstrated in the present study is consistent with several other studies [36-38]. Also, results of the present study indicated a significant increase in psychosocial wellbeing (reduction in psychosocial stress) and significant decrease in WBC in the continuous group over control group. Changes in $\mathrm{VO}_{2}$ max significantly and negatively correlated with changes in WBC and psychosocial 
Table 2. Groups mean \pm SD pretest and posttest values $(\mathrm{N}=217)$.

\begin{tabular}{ccccc}
\hline Variables & $\begin{array}{c}\text { Continuous group pretest } \\
\mathbf{X} \pm \mathbf{S D}\end{array}$ & $\begin{array}{c}\text { Continuous group posttest } \\
\mathbf{X} \pm \mathbf{S D}\end{array}$ & $\begin{array}{c}\text { Control group pretest } \\
\mathbf{X} \pm \text { SD }\end{array}$ & $\begin{array}{c}\text { Control group posttest } \\
\mathbf{X} \pm \text { SD }\end{array}$ \\
\hline $\mathrm{SBP}(\mathrm{mmHg})$ & $170.45 \pm 15.57$ & $157.82 \pm 23.91$ & $160.87 \pm 13.23$ & $13.47 \pm 14.88$ \\
$\mathrm{DBP}(\mathrm{mmHg})$ & $97.56 \pm 7.53$ & $94.83 \pm 7.21$ & $97.17 \pm 1.43$ & $96.10 \pm 2.61$ \\
$\mathrm{VO}_{2} \mathrm{max}(\mathrm{ml} / \mathrm{kg} / \mathrm{min})$ & $20.69 \pm 12.49$ & $28.68 \pm 13.60$ & $21.23 \pm 5.76$ & $22.82 \pm 7.44$ \\
Psychosocial status & $59.94 \pm 9.09$ & $71.69 \pm 5.95$ & $63.93 \pm 10.28$ & $65.27 \pm 10.47$ \\
WBCc $(\mathrm{x} \mathrm{10} / \mathrm{mm})$ & $8.43 \pm 1.80$ & $7.66 \pm 1.37$ & $7.13 \pm 1.30$ & $8.21 \pm 1.60$ \\
\end{tabular}

*significant, $\mathrm{p}<0.05$.

Table 3. Independent t-test between groups changed score (pretest-posttest values) values $(\mathrm{N}=217)$.

\begin{tabular}{|c|c|c|c|}
\hline Variables & $\begin{array}{l}\text { Continuous group changed score } \\
\qquad X \pm \text { SD }\end{array}$ & $\begin{array}{l}\text { Control group changed score } \\
\qquad X \pm \text { SD }\end{array}$ & p-values \\
\hline $\mathrm{SBP}(\mathrm{mmHg})$ & $-13.41 \pm 6.95$ & $2.61 \pm 7.85$ & $0.000^{*}$ \\
\hline $\mathrm{DBP}(\mathrm{mmHg})$ & $-7.41 \pm 6.26$ & $-1.07 \pm 1.76$ & $0.040^{*}$ \\
\hline $\mathrm{VO}_{2} \max (\mathrm{ml} / \mathrm{kg} / \mathrm{min})$ & $7.99 \pm 6.23$ & $1.59 \pm 3.54$ & $0.000^{*}$ \\
\hline Psychosocial status & $10.44 \pm 6.23$ & $1.33 \pm 3.15$ & $0.000^{*}$ \\
\hline $\mathrm{WBCc}(\mathrm{x} \mathrm{10/mm)}$ & $-0.77 \pm 2.15$ & $1.09 \pm 1.69$ & $0.000^{*}$ \\
\hline
\end{tabular}

*significant, $\mathrm{p}<0.05$.

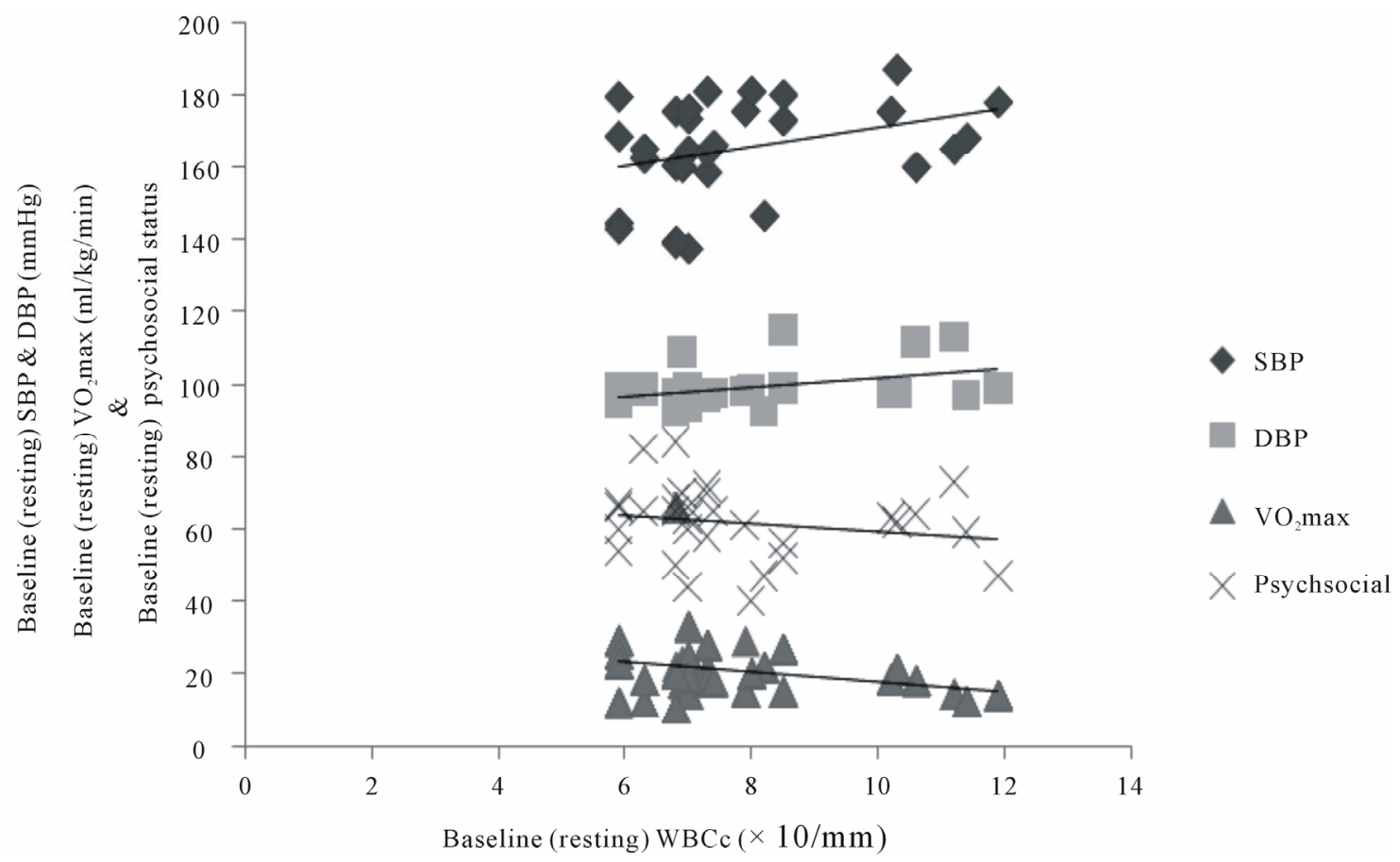

Figure 2. Correlation between training changes in $\mathrm{WBCc}, \mathrm{VO}_{2} \mathrm{max}$, psychosocial status, SBP \& DBP $(\mathrm{N}=217)$. SBP r $=0.344^{* *}$; DBP r $=0.384^{* *} ; \mathrm{VO}_{2} \operatorname{max~} \mathrm{r}=-0.247^{* *}$; Psychosocial status $\mathrm{r}=-0.202^{*}$; significant at $0.01^{* *}$; significant at $0.05^{*}$. 


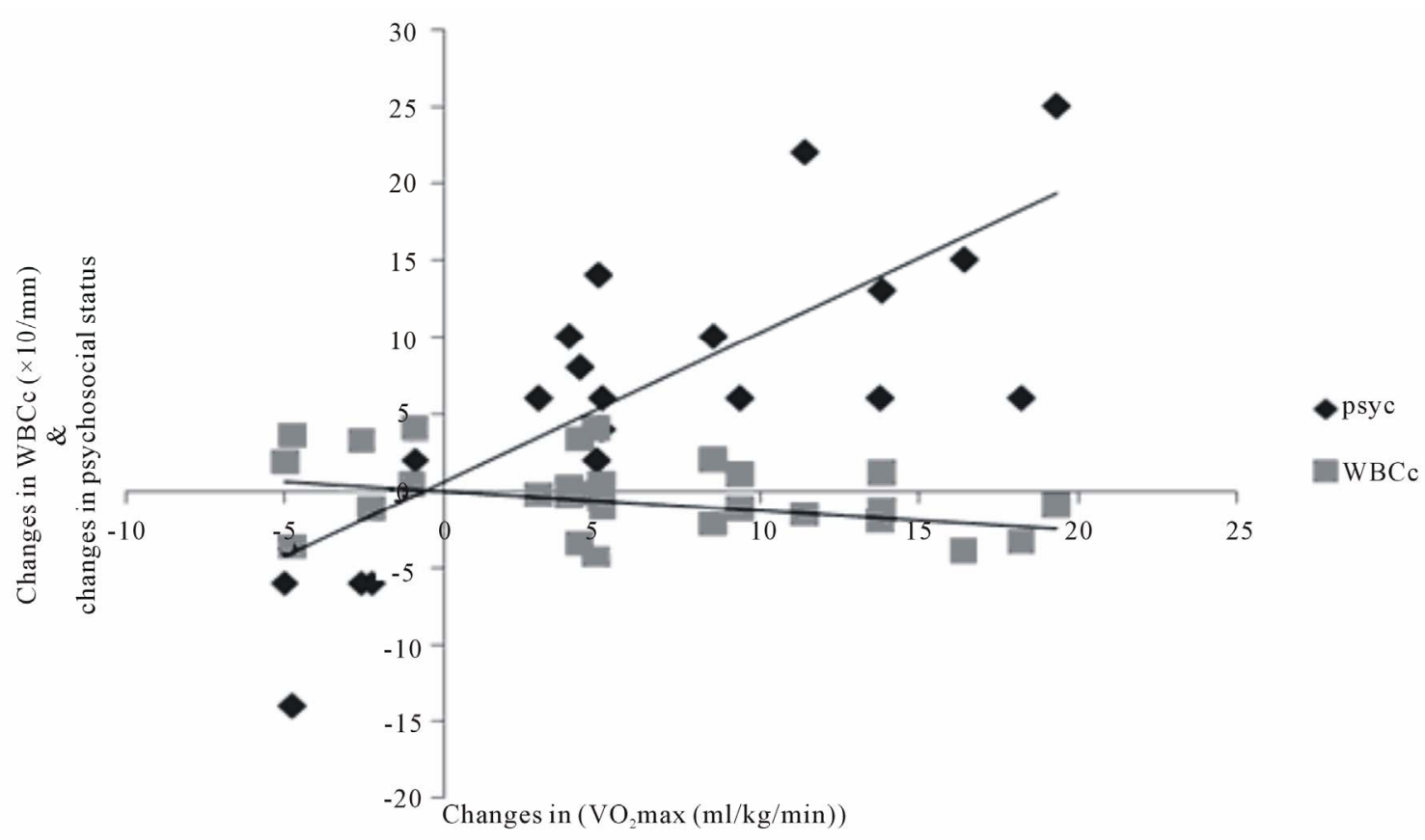

Figure 3. Correlation between training changes in $\mathrm{VO}_{2} \mathrm{max}, \mathrm{WBCc}$ and psychosocial status $(\mathrm{N}=112)$. Psychosocial $\mathrm{r}$ $=0.729^{* *} ; \mathrm{WBC} \mathrm{r}=-0.418^{* *}$; significant at $0.01^{* *}$.

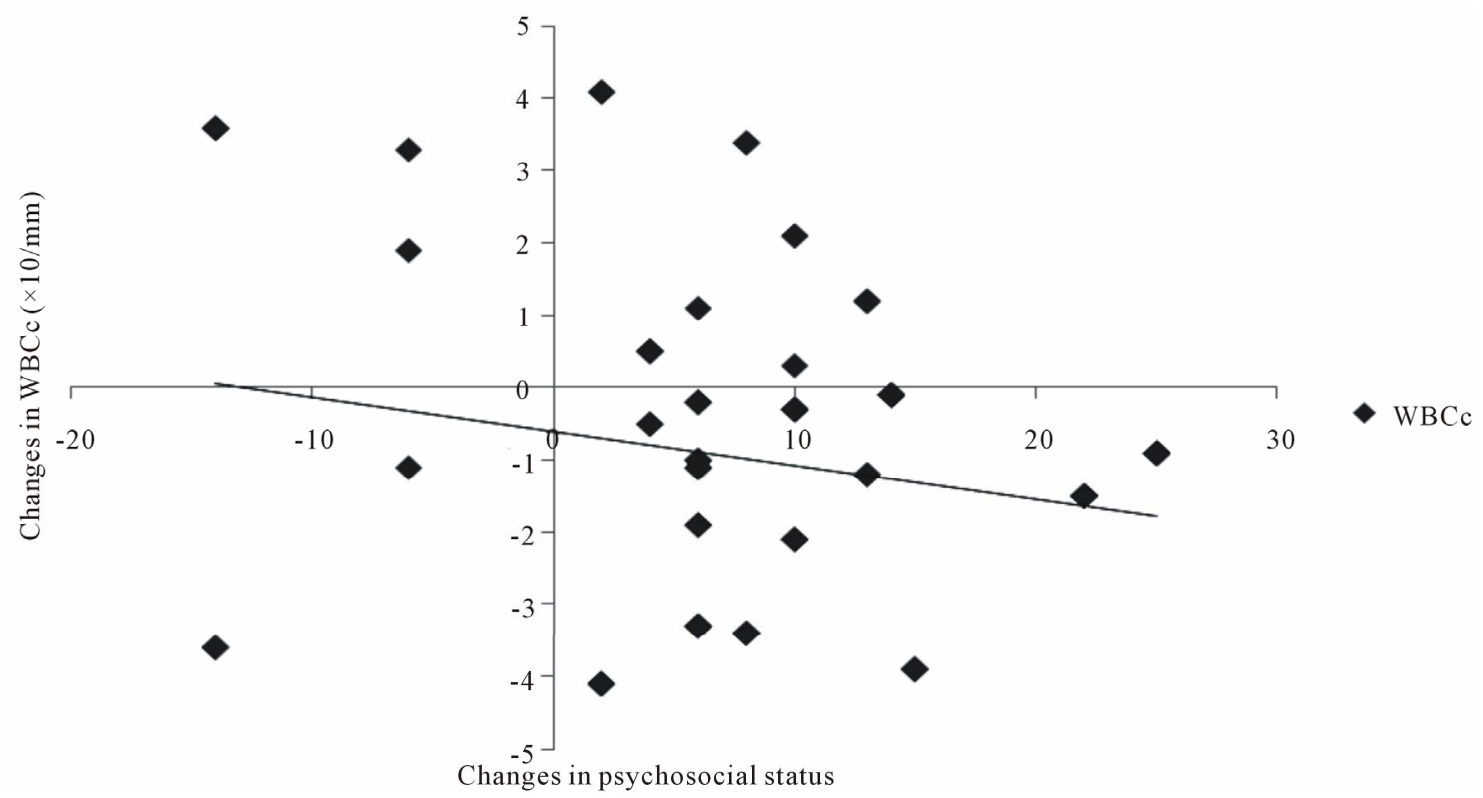

Figure 4. Correlation between training changes in psychosocial status and changes in WBCc $(\mathrm{N}=112)$. WBCc $\mathrm{r}=$ $-0.202^{*}$; significant at $0.05^{*}$.

status. Also changes in WBC significantly and negatively correlated with changes in changes in psychosocial status.

Kullo et al. [39] investigated the effect of aerobic exercise on WBC count, though, on patients with coronary heart disease (CHD). One hundred and seventy two asymptomatic men with CHD (age, $51 \pm 9.3$ years) engaged in a symptomless graded treadmill aerobic exercise. They reported a significant reduction in WBC count and an inverse significant correlation with $\mathrm{VO}_{2} \max (\mathrm{r}=$ $-0.22, p=0.004)$ similar to the finding of the present study. Church et al. [40] also reported a similar finding, in a cross-sectional study of 4057 men examining the age-adjusted resting WBC count levels and risk of having a clinically significant elevation of white blood cell count across nine fitness-body fatness combinations. They reported that fitness was inversely related to the age-ad- 
justed values of WBC count.

A contradictory finding was reported by Shankar et al. [41], though, on normotensive subjects. They studied the relationship between WBC count and physical activity in the development of hypertension. Two thousand four hundred and fifty-nine hypertension-free women and men after adjusting and stratifying by smoking and several other potential confounding factors, they reported nonsignificant effect of moderate physical activity of twice per week on WBC count. Reasons for diversities in findings between the present study and previous study might not be unconnected with the interracial differences that might exist in exercise responses to WBC count.

WBC has been implicated as a risk factor in development hypertension and further development of cardiac events in hypertension. Also, it has been long and well established the therapeutic role of exercise as an adjunct to drug therapy and other life style modification. Various mechanisms have been postulated for the role of exercise in down regulation of BP and other factors in hypertension. However, studies investigating the subjective anti inflammatory role of exercise in the down regulation of WBC count are very few, particularly in hypertensive condition. To our knowledge, this is the first randomized, controlled trial examining the impact of a continuous moderate intensity aerobic training on psychosocial stress and WBC a major biomarker of inflammation in hypertension. The therapeutic anti-inflammatory role of exercise was established in the present study. It also affirmed the therapeutic role of exercise in the down regulation of blood pressure in a large pure black African population study.

\section{CONCLUSION}

Based on the results of the present study, it was concluded that psychosocial stress, elevated WBC and hypertension are interrelated. The study also concludes and supports the recommendations of moderate intensity (continuous) training program as a multi-therapy in blood pressure reduction, anti-inflammatory (WBC) and psychosocial stress management in hypertension. However, the antihypertensive effect of the training programme may be through the suppression of the chronic inflammation such as WBC.

\section{REFERENCES}

[1] Kearney, P.M., Whelton, M., Reynolds, K., Muntner, P., Whelton, P.K. and He, J. (2005) Global burden of hypertension: analysis of worldwide data. Lancet, 365, 217223.

[2] Williams, B., Poulter, N.R., Brown, M.J., Davis, M., McInnes, G.T. and Potter, J.F. (2004) British Hypertension Society. Guidelines for management of hypertension: Re- port of the fourth working party of the British hypertension society, 2004-BHS IV. Journal of Human Hypertension, 18, 139-185. doi:10.1038/sj.jhh.1001683

[3] Tomson, J. and Lip, G.Y. (2005) Blood pressure demographics: Nature or nurture genes or environment? BMC Medicine, 3, 3-6. doi:10.1186/1741-7015-3-3

[4] Boos, C.J. and Lip, G.Y. (2005) Elevated high-sensitive $\mathrm{C}$-reactive protein, large arterial stiffness and atherosclerosis: A relationship between inflammation and hypertension? Journal of Human Hypertension, 19, 511-513. doi:10.1038/sj.jhh.1001858

[5] Vazquez-Oliva, G., Fernandez-Real, J.M., Zamora, A., Vilaseca, M. and Badimon, L. (2005) Lowering of blood pressure leads to decreased circulating interleukin-6 in hypertensive subjects. Journal of Human Hypertension, 19, 457-462. doi:10.1038/sj.jhh.1001845

[6] Bautista, L.E. (2003) Inflammation, endothelial dysfunction, and the risk of high blood pressure: Epidemiologic and biological evidence. Journal of Human Hypertension, 17, 223-230. doi:10.1038/sj.jhh.1001537

[7] Bautista, L.E., Lopez-Jaramillo, P. and Vera, L.M. (2001) Is C-reactive protein an independent risk factor for essential hypertension? Journal of Hypertension, 19, 857-861. doi:10.1097/00004872-200105000-00004

[8] Mugge, A. and Lopex, J.A. (1991) Do leucocytes have a role in hypertension? Hypertension, 17, 331-333. doi:10.1161/01.HYP.17.3.331

[9] Sinisalo, J., Paronen, J., Muttila, K.J., Syrjata, M., Alfthan, G., Palosuo, T., Nieminen, M.S. and Vaorala, O. (2000) Relation of inflammation to vascular friction in patients with coronary heart disease. Athrosderosis, 49, 403-411. doi:10.1016/S0021-9150(99)00333-0

[10] Ito, B.R., Schmid-Schnobein, G. and Engler, R.L. (1990) Effect of leucocyte activation on myocardial vascular resistance. Blood Cells, 16, 145-163.

[11] Friedman, G.D., Selby, J.V. and Qveseroberry, C.P. (1990) The leukocyte count a predictor of hypertension. Journal of Clinical Epidmiology, 43, 907-911. doi:10.1016/0895-4356(90)90074-Y

[12] Kuchel, O. (1983) The autonomic nervous system and blood pressure regulation in human hypertension. In Genest, J., Kuchel, O., Hamet, P. and Cantin, M., Eds., Hypertension: Pathophysiology and Treatment, 2nd Edition, McGrawHill, New York, 140-160.

[13] Bruunsgaard, H. (2005) Physical activity and modulation of systemic low-level inflammation. Journal of Leukocyte Biology, 78, 819-835. doi:10.1189/jlb.0505247

[14] Kasapis, C. and Thompson, P.D. (2005) The effects of physical activity on serum C-reactive protein and inflammatory markers: A systematic review. Journal of the American College of Cardiology, 45, 1563-1569. doi:10.1016/i.jacc.2004.12.077

[15] Mohamed-Ali, V., Bulmer, K. and Clarke, D. (2000) Adrenergic regulation of proinflammatory cytokines in humans. International Journal of Obesity and Related Metabolic Disorders, 24, S154-S155. doi:10.1038/sj.ijo.0801311

[16] MacDonald, J.R., Hogben, C.D., Tarnopolski, M.A. and 
McDougall, J.G. (2001) Post exercise hypertension is sustained during subsequent bouts of mild exercise and simulated activities of daily living. Journal of Human Hypertension, 15, 567-571. doi:10.1038/sj.jhh.1001223

[17] Pearson, T.A., Blair, S.N. and Daniels, S.R. (2001) AHA guidelines for primary prevention of cardiovascular disease and stroke: 2002 update: Consensus panel guide to comprehensive risk reduction for adult patients without coronary or other atherosclerotic vascular diseases. American Heart Association Science Advisory and Coordinating Committee. Circulation, 106, 388-391. doi:10.1161/01.CIR.0000020190.45892.75

[18] Peake, J.M., Suzuki, K., Hordern, M., Wilson, G., Nosaka, K. and Coombes, J.S. (2005) Plasma cytokine changes in relation to exercise intensity and muscle damage. European Journal of Applied Physiology, 95, 514-521. doi:10.1007/s00421-005-0035-2

[19] Nicklas, B.J. and Brinkley, T.E. (2009) Exercise as a treatment for chronic inflammation in older adults. Exercise and Sport Sciences Reviews, 37, 165-170.

[20] Ruggiero, C., Metter, E.J. and Cherubini, A. (2010) Limited systemic sclerosis patients with pulmonary arterial hypertension show biomarkers of inflammation and vascular injury. PLoSOne, 17, e12106.

[21] Nicklas, B.J., Hsu, F.C. and Brinkley, T.J. (2008) Exercise training and plasma C-reactive protein and interleukin-6 in elderly people. Journal of the American Geriatrics Society, 56, 2045-2052. doi:10.1111/j.1532-5415.2008.01994.x

[22] Wong, N.D., Pio, J., Valencia, R. and Thakal, G. (2001) Distribution of C-reactive protein and its relation to risk factors and coronary heart disease risk estimation in the National Health and Nutrition Examination Survey (NHANES) III. Preventive Cardiology, 4, 109-114. doi:10.1111/j.1520-037X.2001.00570.X

[23] Hall, W.D., Ferrario, C.M., Moore, M.A., Hall, J.E., Flack, J.M. and Cooper, W. (1997) Hypertension-related morbidity and mortality in the southeastern United States. The American Journal of the Medical Sciences, 313, 195-209. doi:10.1097/00000441-199704000-00002

[24] American College of Sport Medicine (1991) Guide lines for exercise testing and Prescription. 4th Edition, Lea \& Febiger, Philadelphia.

[25] Townsend, R.R., Mcfadden, T.C., Ford, V., Cadee, J.A. (2004) A randomized double blind, placebo-controlled trial of casein protein hydrolysnte (C12 peptide) in human essential hypertension. American Journal of Hypertension, 17, 1056-1058. doi:10.1016/j.amjhyper.2004.06.018

[26] Musa, D.I., Ibrahim, D.M. and Toriola, A.L. (2002) Cardiorespiratory fitness and risk factors of CHD in pre-adolescent Nigerian girls. Journal of Human Movement Studies, 42, 455.

[27] International Society for the Advancement of Kinanthropometry (ISAK) (2001) International standards for anthropometric assessment. ISAK, Patche Fstroom.

[28] Bachorik, P.S. (1982) Collection of blood sample for li- poprotein analysis. Clinical Chemistry, 28, 1375-1378.

[29] Barbieri, M., Ferrucci, L., Corsi, A.M., Macchi, C., Lauretani, F., Bonafe, M., Olivieri, F., Giovagnetti, S., Franceschi, C. and Paolisso, G. (2003) Is chronic inflammation a determinant of blood pressure in the elderly? AJH, 16, 537-543.

[30] Dacie, J.V. and Lewis, S.M. (1975) Practical hematology, 5th Edition, Churchill Livingstone, London.

[31] Stephens, T. and Graig, C.L. (1990) The well being of Canadian: highlights of the 1988 Cambell Survey. Ottawa Canadian Fitness and Lifestyle Research Institute.

[32] American College of Sports Medicine (1995) ASCM's guidelines for exercise testing and prescription. 5th Edition, Williams \& Wilkins, Baltimore.

[33] Katzung, B.G. (1998) Basic and clinical pharmacology. 7th Edition, Lange Medical Books/Craw Hill, New York.

[34] Mancia, G., Ferari, L., Gregorini, L., Leonett, L., Terzoli, L., Biachini, C. and Zanchetti, A. (1980) Effects of treatment with methyldopia on basal haemodynamic and on rural control. In: Robertson, J.S., Pickering, G.W. and Goldwell A.D.S., Eds., The Therapeutics of Hypertension, Royal Society of Medicine and Academic Press Inc. Ltd., London, 70-78.

[35] Salako, L.A. (1976) Treatment of hypertension: Cardiovascular disease in Africa. Ciba Geigy Ltd., Ibadan.

[36] American College of Sport Medicine (1993) Physical activity, physical fitness and hypertension. Medicine \& Science in Sports \& Exercise, 25, i-x. doi:10.1249/00005768-199310000-00024

[37] Laterza, M.C., Demator, L.D., Trombetta, I.C., Braza, A.M., Roveda, F., Alves, M.J., Negrao, C.E. and Rondon, M.U. (2007) Exercise training restores baroreflex sensitivity in never trained hypertensive patients. Hypertension, 49, 1298-1306. doi:10.1161/HYPERTENSIONAHA.106.085548

[38] Westhoff, T.H., Franke, N., Schmidt, S., Valbracht-Israng, K., Meissner, R., Yildirim, H., Schlattmann, P., Zidek, W. and Vandergiet, M. (2007) Too old benefit from sports? The cardiovascular effects of exercise training in elding subjects treated for isolated systolic hypertension. Kidney Blood Press Research, 30, 240-247. doi:10.1159/000104093

[39] Kullo, D.I., Khaleghi, M. and Hensrud, D.D. (2007) Markers of inflammation are inversely associated with $\mathrm{VO}_{2} \mathrm{max}$ in symptomatic men. Journal of Applied Physiology, 102, 1374-1379. doi:10.1152/japplphysiol.01028.2006

[40] Church, T.S., Finley, C.E., Earnest, C.P., Kampert, J.B., Gibbon, L.W. and Blair, S.N. (2003) Relative associations of fitness and fatness to fibrinogen, white blood count, uric and metabolic syndrome. International Journal of Obesity, 26, 805-813.

[41] Shankar, A., Klein, B.E. and Klien, R. (2001) Relationship between white blood cell count and incident hypertension. American Journal of Hypertension, 17, 233-239. doi:10.1016/j.amjhyper.2003.11.005 